\title{
Exhaled volatile organic compounds for phenotyping chronic obstructive pulmonary disease: a cross-sectional study
}

\author{
Maria Basanta', Baharudin Ibrahim', Rachel Dockry', David Douce², Mike Morris², Dave Singh', \\ Ashley Woodcock ${ }^{1}$ and Stephen J Fowler ${ }^{1,3^{*}}$
}

\begin{abstract}
Background: Non-invasive phenotyping of chronic respiratory diseases would be highly beneficial in the personalised medicine of the future. Volatile organic compounds can be measured in the exhaled breath and may be produced or altered by disease processes. We investigated whether distinct patterns of these compounds were present in chronic obstructive pulmonary disease (COPD) and clinically relevant disease phenotypes.

Methods: Breath samples from 39 COPD subjects and 32 healthy controls were collected and analysed using gas chromatography time-of-flight mass spectrometry. Subjects with COPD also underwent sputum induction.

Discriminatory compounds were identified by univariate logistic regression followed by multivariate analysis: 1. principal component analysis; 2. multivariate logistic regression; 3. receiver operating characteristic (ROC) analysis.

Results: Comparing COPD versus healthy controls, principal component analysis clustered the 20 best-discriminating compounds into four components explaining $71 \%$ of the variance. Multivariate logistic regression constructed an optimised model using two components with an accuracy of $69 \%$. The model had $85 \%$ sensitivity, $50 \%$ specificity and ROC area under the curve of 0.74 . Analysis of COPD subgroups showed the method could classify COPD subjects with far greater accuracy. Models were constructed which classified subjects with $\geq 2 \%$ sputum eosinophilia with ROC area under the curve of 0.94 and those having frequent exacerbations 0.95. Potential biomarkers correlated to clinical variables were identified in each subgroup.
\end{abstract}

Conclusion: The exhaled breath volatile organic compound profile discriminated between COPD and healthy controls and identified clinically relevant COPD subgroups. If these findings are validated in prospective cohorts, they may have diagnostic and management value in this disease.

Keywords: Chronic obstructive pulmonary disease, Biomarkers, Breath tests, Metabolomics

\section{Background}

Chronic obstructive pulmonary disease (COPD) is defined clinically on the basis of airflow obstruction [1,2]. This simple definition does not reflect the heterogeneous nature of COPD with individual variations in pathophysiology, aetiology, symptoms, prognosis and treatment response. For example, chronic cough and mucus are poor

\footnotetext{
* Correspondence: stephen.fowler@manchester.ac.uk

${ }^{1}$ Respiratory Research Group, Faculty of Medical and Human Sciences, University of Manchester, Manchester Academic Health Science Centre, and NIHR Translational Research Facility in Respiratory Medicine, University Hospital of South Manchester, Southmoor Road, Manchester M23 9LT, UK ${ }^{3}$ Lancashire Teaching Hospitals NHS Foundation Trust, Preston, UK Full list of author information is available at the end of the article
}

prognostic features [3], frequent exacerbations are associated with progressive loss in lung function [4], and the presence of sputum eosinophilia predicts response to inhaled corticosteroids [5]. Identifying these and other subtypes will be critical for appropriate management of these patients in the future, allowing targeted therapy and more accurate disease monitoring [6].

The breath contains as yet unknown numbers of volatile organic compounds (VOCs), both exogenous and endogenous in origin. Endogenous VOCs will arise not only from all levels of the airway but also the circulation via the alveolar-capillary interface, as a result of metabolic processes occurring both in health and disease. Exogenous
C Biomed Central

(c) 2012 Basanta et al.; licensee BioMed Central Ltd. This is an Open Access article distributed under the terms of the Creative Commons Attribution License (http://creativecommons.org/licenses/by/2.0), which permits unrestricted use, distribution, and reproduction in any medium, provided the original work is properly cited. 
VOCs can be altered by processes within the airways, both physical (e.g. adsorption into surface liquid) and biochemical (e.g. oxidation). Controlled measurement of these exhaled compounds could therefore potentially give us novel insights into airway biology, physiology and pharmacology, and provide us with phenotype-specific biomarkers. Previous work has suggested that patterns of VOCs in breath gas may be useful in identifying patients with COPD [7], [8], and that individual compounds correlate with inflammatory cell numbers and markers of activation [9], whilst another method for metabolomic analysis has employed nuclear magnetic resonance spectroscopy of exhaled breath condensate to classify COPD and healthy controls [10]. To our knowledge the possibility of identifying clinically relevant disease phenotypes, such the eosinophilic or exacerbation-prone phenotypes, has not been investigated.

We have developed a method that enables us to noninvasively sample the late-expiratory breath in patients with respiratory disease, and used it to discriminate similarly relevant phenotypes in asthma [11]. To ensure detection of potential compounds of interest present at extremely low concentration we have allied our sampling methodology (which concentrates a high volume of breath) to highly sensitive separation and detection instrumentation [gas chromatography-time-of-flight mass spectrometry (GC-ToF-MS)]. The aim of the current study was to use this to characterise the exhaled VOC profile in patients with COPD in comparison to healthy controls. We have then investigated whether VOC profiles can discriminate subgroups defined by inflammatory-cell phenotype and exacerbation frequency.

\section{Methods}

\section{Subjects}

Subjects were recruited from the Medicines Evaluation Unit clinical trials database, University Hospital of South Manchester, UK. Some of the COPD subjects were also taking part in the Evaluation of COPD Longitudinally to Identify Predictive Surrogate End-points (ECLIPSE) study [12]. The study was approved by a local Research Ethics Committee and subjects provided written informed consent. All COPD subjects had a clinical diagnosis of the disease, and met Global Initiative for Chronic Obstructive Lung Disease (GOLD) criteria [1].

\section{Inclusion and exclusion criteria}

Participants with COPD had baseline post-bronchodilator forced expiratory volume in one second (FEV1)/forced vital capacity (FVC) less than 0.7 and a smoking history of at least 10 pack years. Healthy volunteers had baseline FEV1 greater than $80 \%$ predicted, FEV1/FVC greater than 0.7 , and were categorised as healthy smokers (current smokers with at least 10 pack year history) or healthy never-smokers. Abstinence from smoking was checked by measurement of exhaled carbon monoxide with a cut-off of $\leq 5 \mathrm{ppm}$ (Smokerlyzer, Bedfont Scientific, Maidstone, UK). Exclusion criteria included: other chronic respiratory disorders or systemic inflammatory disease, (e.g. rheumatoid arthritis), malignancy within last five years, moderate or severe exacerbation (requiring oral corticosteroids and/ or antibiotics) within the four weeks prior to study visit (all courses of oral corticosteroids and antibiotics must have been completed at least 2 weeks before study visit), long term (more than three months) oral corticosteroids.

\section{Study procedures}

Subjects were asked to refrain from eating, drinking (except for water) and smoking for two hours prior to breath collection, and from using their inhaled medication on the morning of the visit. Demographic data were collected, and subjects from the ECLIPSE cohort had prospectively recorded exacerbation frequency in the previous year. Study procedures were then performed in the following order: exhaled breath collection, spirometry, and sputum induction.

\section{Spirometry}

Spirometry was performed according to American Thoracic Society / European Respiratory Society guidelines [13], using the MasterScope CT pneumotach (Viasys $\mathrm{GmbH}$, Hoechberg, Germany).

\section{Sputum induction}

Sputum induction was performed using inhaled hypertonic saline in increasing strengths $(3,4$, and $5 \%)$ from an ultrasonic nebuliser (Medix Sonix 2000, Clement Clarke, Essex, UK) as previously described [14]. Sputum induction was stopped early if the patient's $\mathrm{FEV}_{1}$ fell below the safety cut-off ( $80 \%$ of baseline). Sputum samples were stored on ice and processed within two hours. A minimum of 400 leukocytes were counted. Slides containing $>20 \%$ squamous cells were regarded as representing salivary contamination and excluded.

\section{Exhaled breath collection and analysis}

All the breath samples were collected in the same room, used solely for this study, minimising the effect of variation in background air. Breath samples were collected and analysed as previously described $[11,15]$. In brief subjects breathed VOC-filtered air, while respiratory pattern was tracked via a pressure transducer and visualised using bespoke software, enabling selective sampling of late expiratory breath, minimising contamination from the mouth, nose and deadspace. Sampling was performed during tidal breathing, and commenced after the subject had been breathing VOC filtered air for five minutes, allowing a degree of equilibration as well as ensuring the 
subjects were relaxed at the start of sampling. Three litres of selected exhaled breath per sample were collected directly onto adsorbent tubes packed with Tenax TA/Carbotrap (Markes International, Rhondda Cynon Taff, UK) for analysis by GC-ToF-MS. Due to differing tidal volumes between subjects, and with sampling triggered only during late expiration, collection of each $3 \mathrm{~L}$ sample typically took between five and seven minutes.

\section{Sample analysis and data processing}

Samples were analysed in random order by thermal desorption (TD) followed by GC-ToF-MS. To ensure the instrument response was precise for the wide range of VOCs that we expected to detect, a quality control (QC) was made up of a mixture of 21 VOCs (Sigma-Aldrich; purity 99\%; solvent HPLC grade methanol) and run through the instrument before each study sample. A range of concentrations from $\mathrm{pg} / \mu \mathrm{l}$ to $\mathrm{ng} / \mu \mathrm{l}$ were prepared to calibrate the instrument. D5bromobenzene was added to the breath samples and $\mathrm{QC}$ as an internal standard prior to analysis at a 1.5 $\mathrm{ng} / \mu \mathrm{l}$ concentration (RSD 5.14\%). The analytical methodology, including details of the QC and internal standard, is described elsewhere [15]. Instrumental and intra-individual (day-to-day) reproducibility have previously been shown to be excellent for breath samples analysed by GC-ToF-MS [16].

Data were acquired and pre-processed using the onboard software package MassLynx (Waters Corp., Manchester UK). Pre-processing entails detection, spectral deconvolution and alignment of potential markers. Markers were presented as exact mass and retention time pairs and the intensity of each marker for each sample was recorded. Principal component analysis (PCA) was performed on the marker intensities to visualise any major differences between sample sets. In parallel Automated Mass Spectral Deconvolution and Identification System (AMDIS) was used to extract spectra for individual components from GC-MS data and identifies compounds by matching these spectra against specialised libraries. A reference file containing straight chain alkanes was used to build up a retention indices library to allow alignment of data, and a library of 487 compounds created by confirming the identity of compounds against the National Institute of Standards and Technology (NIST) library and elemental composition of molecular ions and their fragments. Absolute error was acceptable at values lower than $1.5 \mathrm{mDa}$. Internal standard peak area was extracted and relative intensities of library compounds calculated (i.e. normalised to the internal standard). Statistical analysis was performed on a final data matrix containing relative peak areas of library components for all the samples.

\section{Statistical analysis}

All data were analysed using SPSS version 15 (SPSS Inc., Chicago, IL, USA). For demographic data, descriptive statistics were used, with between group comparisons made using Pearson chi square, parametric (students t-test) and non parametric tests (Mann Whitney U) where appropriate.

The primary comparison of interest was the breath profile of COPD patients versus healthy controls. It was not possible to calculate a sample size for this study as we had no a priori information regarding the identity or variance of potential compounds of interest. We anticipated that smoking status and inhaled corticosteroid use would represent obvious confounders to the analysis, so planned to stratify by current smoking status, and COPD subgroup analysis by inhaled corticosteroid use. To investigate the potential for the breath profile to predict clinical phenotypes, we planned further COPD subgroup analyses by sputum eosinophilia and exacerbation frequency. Cut-offs for sputum eosinophilia and exacerbation frequency were pragmatic: a cut-off for sputum eosinophils of $1 \%$ can identify non-responders to inhaled corticosteroids in COPD [5] whereas higher cut-offs such as $2 \%$ are typically used in severe asthma [17]; there are no similar data to guide a cut-off for exacerbation frequency, so we used the median value in our cohort of two exacerbations in the previous 12 months. The aim of the data analysis was to generate a valid model for discriminating between groups. Our analytical strategy has previously been published [11], and is summarised in Figure 1. One approach in metabolomics for dealing with the very high number of variables in comparison to the number of subjects is to perform initial data reduction prior to multivariate analysis (e.g. $[18,19]$ ). For each comparison of interest this was achieved by between group univariate analysis (logistic regression) for each of the identified compounds, in order to achieve a balance between optimising the validity of the subsequent principal component analysis (PCA), whilst limiting the risk of discarding potentially important compounds. The principal components (PCs) were then entered into multivariate logistic regression to generate a best-fit model for between group discrimination, and the performance of this model described by receiver operating characteristics [20]. Discriminant function analysis (DFA) with leave-one-out cross validation (LOOCV) was used in parallel to check the performance of the model. The relationship between specific VOCs forming the PCs used in each model and the corresponding phenotype-defining parameters (e.g. sputum eosinophil count, number of exacerbations per year) was explored further using Pearson's Correlation Coefficient. 


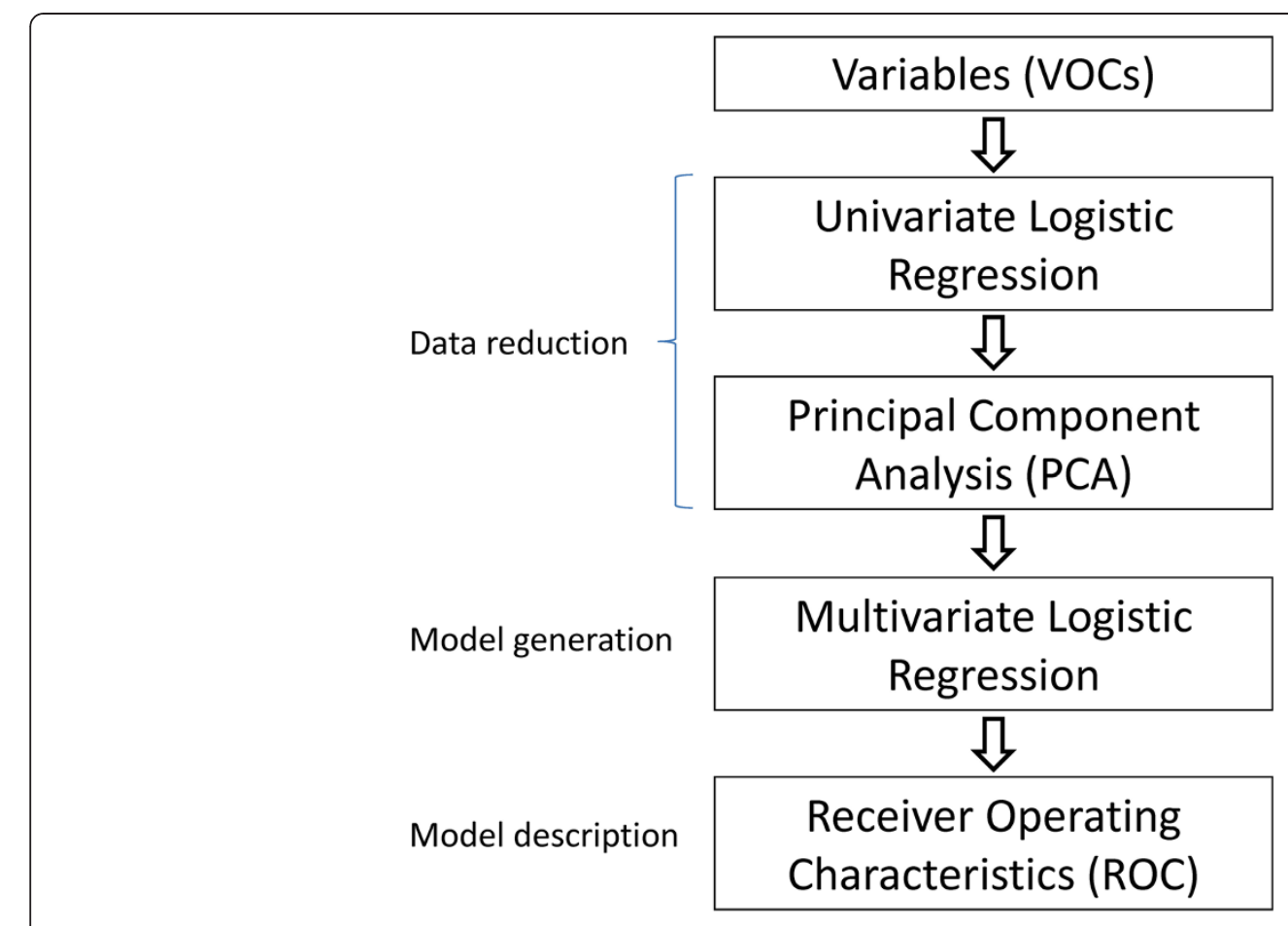

Figure 1 Flow-chart summarising the statistical approach adopted for variable reduction and model generation.

\section{Results}

Breath samples were collected from a total of 71 subjects (39 COPD and 32 healthy controls), including 23 COPD subjects recruited from the ECLIPSE cohort. Demographic details are shown in Table 1. Apart from the expected differences in lung function parameters, the COPD group were also older and had more comorbidities than the healthy group. None of the included subjects in either group had a history of renal or hepatic impairment.

\section{COPD versus healthy controls}

From the 487 compounds identified, those with COPD versus healthy control $\mathrm{p}<0.10(\mathrm{n}=20)$ were retained for inclusion in the PCA. Four PC's with Eigenvalues more than one and explaining $70.8 \%$ of the total variance were derived. When these four PC's were used in logistic regression analysis, a model consisting of PC 1 and PC 4 significantly predicted samples from subjects with COPD. This model is shown in Table 2, and correctly classified $33(84.6 \%)$ of COPD samples and 16 healthy controls (50.0\%). A plot of the PCs used in the model is shown in Figure 2. The ROC parameters for the model were: sensitivity $85 \%$, specificity $50 \%$, precision $67 \%$, accuracy 69\%, area under ROC curve (AUROC) 0.74. These results were confirmed with discriminant function analysis which showed the two factors significantly discriminated the two groups with accuracy of $70.4 \%$ [Wilk's lambda $=0.84$, chi square $=11.909$, $\mathrm{p}=0.003]$, and this accuracy was confirmed using
LOOCV which also showed accuracy of $70 \%$. A list of the putative compounds (six of which were aldehydes) contributing to the discriminatory model is shown in Table 3.

Table 1 Demographic data for patients with COPD and healthy controls shown as mean (SD) or \%

\begin{tabular}{|c|c|c|c|}
\hline & & COPD $(n=39)$ & Healthy $(n=32)$ \\
\hline \multicolumn{2}{|l|}{ Age, yrs } & $65.7(6.8)$ & $55.3(7.1) *$ \\
\hline \multicolumn{2}{|l|}{ Gender ( $\%$ male) } & 67 & 47 \\
\hline \multirow[t]{4}{*}{ Smoking status (\%): } & Current & 31 & 31 \\
\hline & Ex & 69 & 0 \\
\hline & Never & 0 & 69 \\
\hline & Pack years & $45.6(18.9)$ & $37.3(19.1)$ \\
\hline \multicolumn{2}{|l|}{$\mathrm{FEV}_{1}, \mathrm{I}$} & $1.48(0.5)$ & $3.26(0.8) *$ \\
\hline \multicolumn{2}{|l|}{$\mathrm{FEV}_{1}, \%$ predicted } & $54.6(15.4)$ & $102.4(12.1)^{*}$ \\
\hline \multicolumn{2}{|l|}{ FVC, I } & $3.12(0.8)$ & $4.20(0.9) *$ \\
\hline \multicolumn{2}{|l|}{ FVC, $\%$ predicted } & $89.7(17.6)$ & $113.3(14.6) *$ \\
\hline \multicolumn{2}{|l|}{$\mathrm{FEV}_{1} / \mathrm{FVC}$} & $49.2(13.1)$ & $77.5(6.6) *$ \\
\hline \multicolumn{2}{|l|}{$\mathrm{BMI}, \mathrm{kg} / \mathrm{m}^{2}$} & $27.8(5.6)$ & $27.4(3.6)$ \\
\hline \multicolumn{2}{|c|}{ GOLD class I/II/III/IV (\%) } & $2 / 19 / 16 / 2$ & NA \\
\hline \multicolumn{2}{|c|}{ Inhaled corticosteroids (\%) } & 64 & NA \\
\hline \multicolumn{2}{|c|}{ Dose, $\mu \mathrm{g}$ BDP equivalent } & $842(978)$ & NA \\
\hline \multicolumn{2}{|c|}{ Long acting $\beta_{2}$-agonists (\%) } & 56 & NA \\
\hline \multicolumn{2}{|c|}{ Long acting antimuscarinics (\%) } & 56 & NA \\
\hline
\end{tabular}

${ }^{*} \mathrm{p}<0.05$ for COPD versus healthy controls.

GOLD = Global Initiative for Chronic Obstructive Lung Disease [1]; $\mathrm{BDP}=$ beclomethasone dipropionate. 
Table 2 Logistic regression model for COPD versus healthy controls

\begin{tabular}{lcccc}
\hline B (SE) & P value & Odds ratio & $\begin{array}{c}95 \% \text { Confidence } \\
\text { interval for } \\
\text { odds ratio }\end{array}$ \\
\hline PC 1 & $-0.751(0.366)$ & 0.040 & 0.472 & 0.230 to 0.967 \\
\hline PC 4 & $0.549(0.284)$ & 0.054 & 1.731 & 0.992 to 3.022 \\
\hline Constant & $0.159(0.265)$ & & & \\
\hline
\end{tabular}

We speculated that this relatively poor discrimination may have been due to the dominating effect of cigarette smoke-related VOCs in some samples, and therefore studied subgroup comparisons based on smoking status. When comparing ex-smokers with COPD with healthy non-smokers the multivariate model accuracy was 73\%, and ROC parameters: sensitivity $89 \%$, specificity $55 \%$ and AUROC 0.77. When data from current smokers only were examined, the resultant model had accuracy $91 \%$ and ROC sensitivity $92 \%$, specificity $90 \%$ and AUROC 0.98.

We investigated whether any of the discriminatory compounds were likely to arise from a corticosteroid effect in the COPD group. Multivariate logistic regression generated a model which discriminated the COPD subjects taking inhaled steroid $(\mathrm{n}=25)$ from those not on inhaled steroid $(\mathrm{n}=14)$ with accuracy of $74 \%$ and AUROC of 0.83 . Of the discriminatory

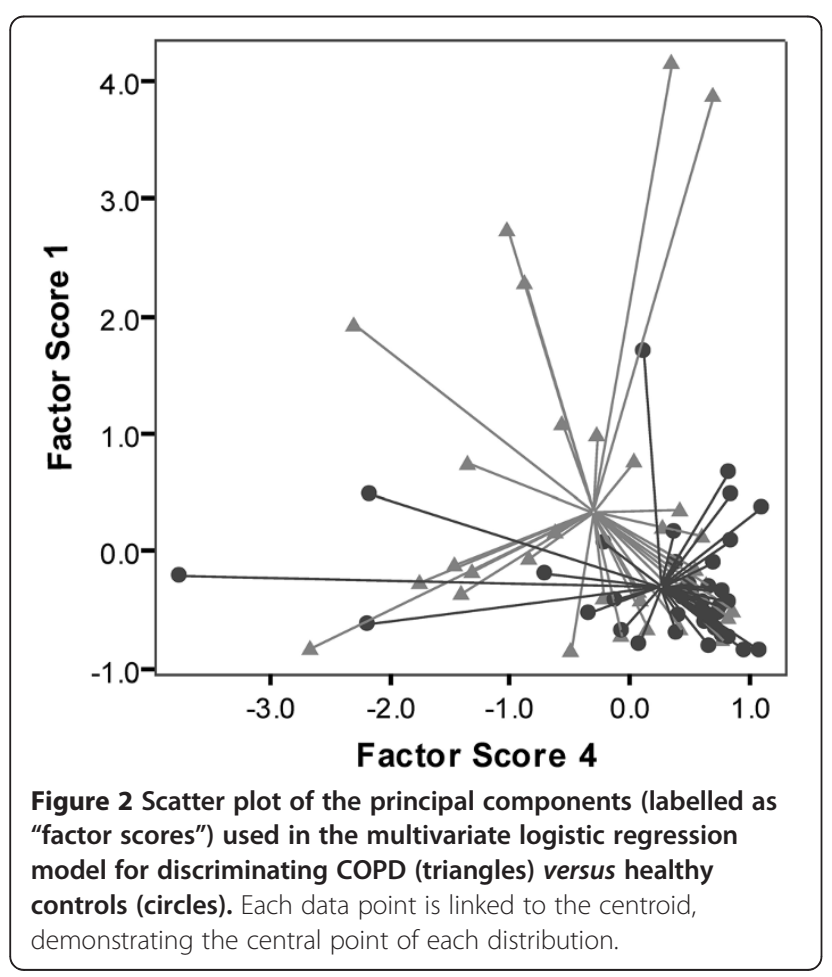

Table 3 Empirical formulae and putative identification of volatile organic compounds used in the model classifying COPD and healthy subjects, grouped by principal component (PC)

\begin{tabular}{|c|c|c|}
\hline PC & Loading & Compound ID \\
\hline \multirow[t]{8}{*}{1} & .987 & Undecanal $\mathrm{C}_{11} \mathrm{H}_{22} \mathrm{O}$ \\
\hline & .949 & Hexanal $\mathrm{C}_{6} \mathrm{H}_{12} \mathrm{O}$ \\
\hline & .901 & Dodecanal $\mathrm{C}_{12} \mathrm{H}_{24} \mathrm{O}$ \\
\hline & .874 & Decanal $\mathrm{C}_{10} \mathrm{H}_{20} \mathrm{O}$ \\
\hline & .867 & Nonanal $\mathrm{C}_{9} \mathrm{H}_{18} \mathrm{O}$ \\
\hline & .764 & Pentadecanal- $\mathrm{C}_{15} \mathrm{H}_{30} \mathrm{O}_{2}$ \\
\hline & .741 & Oxirane, dodecyl- $\mathrm{C}_{14} \mathrm{H}_{28} \mathrm{O}$ \\
\hline & .740 & $\begin{array}{l}\mathrm{C}_{8} \mathrm{H}_{14} \mathrm{O}_{3} \mathrm{Cyclohexanol} \text {, 5-methyl-2-(1-methylethyl)-, } \\
{[1 \mathrm{R}-(1 \mathrm{a}, 2 \mathrm{a}, 5 \mathrm{a})]-\mathrm{C}_{10} \mathrm{H}_{20} \mathrm{O}}\end{array}$ \\
\hline \multirow[t]{3}{*}{4} & -.829 & $\begin{array}{l}\text { Butanoic acid, 2,2-dimethyl-3-oxo-, } \\
\text { ethyl ester } \mathrm{C}_{8} \mathrm{H}_{14} \mathrm{O}_{3}\end{array}$ \\
\hline & -.710 & Pentanoic ac $\mathrm{C}_{5} \mathrm{H}_{10} \mathrm{O}_{2}$ \\
\hline & -.498 & Furan,2-pentyl $\mathrm{C}_{9} \mathrm{H}_{14} \mathrm{O}$ \\
\hline
\end{tabular}

Also shown are PC loadings; loadings closer to one indicate compounds with a higher influence in the $P C$.

compounds included in the COPD versus healthy model (Table 3), only undecanal was also found amongst the compounds included in the steroid model.

\section{Clinical subgroup analysis}

Demographic details of the subgroups are shown in Table 4.

a) Sputum eosinophilia

There were no significant demographic differences between subjects with eosinophilic or non-eosinophilic sputum using either cut-off ( $1 \%$ or $2 \%$ ) in terms of age, gender or lung function. Eleven of 24 COPD subjects with evaluable sputum samples had eosinophil count $\geq 1 \%$, and six $\geq 2 \%$. The logistic regression models had accuracy of $79 \%$ and $92 \%$, AUROC of 0.90 and 0.94 , and LOOCV accuracy of $75 \%$ and $88 \%$ respectively. Plots of the PCs used in the model are shown in Figures $3 \mathrm{a}$ and $3 \mathrm{~b}$, the ROC curve in Figure 4, and compounds underlying the PC's in Table 5.

b) Exacerbation frequency

Data on the number of exacerbations in the previous 12 months were available for the 23 COPD subjects recruited from the ECLIPSE cohort. Thirteen had had two or more exacerbations in that time. Logistic regression predicted the group with frequent exacerbations with an accuracy of $87 \%$, area under ROC curve 0.95 , and LOOCV accuracy of $83 \%$. A plot of the PC's is shown in Figure 3c, the ROC curve in Figure 4, and relevant compounds in Table 5. 
Table 4 Demographic details for subgroup comparisons. Data are shown as mean (SD), except for gender

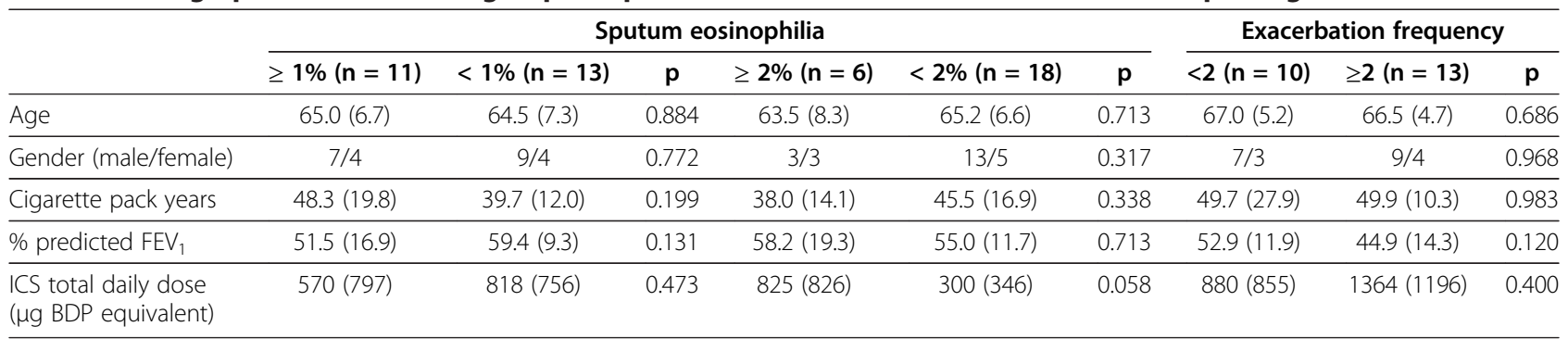

\section{Discussion}

We have shown that this technique for breath collection paired with metabolomic VOC analysis by GC-ToF-MS is able to classify COPD from healthy controls with moderate accuracy. However we were able to demonstrate much greater accuracy when looking at subgroups of clinical interest such as smokers with COPD versus asymptomatic smokers, and COPD subjects with sputum eosinophilia, or those liable to suffer frequent exacerbations. If validated in prospective cohorts, this technique may provide a non-invasive method for phenotyping COPD in the future, with clinical applications for example in personalised therapeutics and prognosis.

Recent data have also shown discrimination between COPD and healthy controls using GC-MS, but based upon analysis of single breath samples [7]. Current work in metabolomic analysis of exhaled VOCs is exploratory and aimed at discovering potential novel biomarkers, so it is critical that the sensitivity of the detection system be optimised. Each of our breath samples contains the VOCs absorbed from 3 litres of late-expiratory air, typically representing 50 to 100 breaths per subject. Paired with GC-ToF-MS, we have a highly sensitive methodology for both absorption and detection of VOCs that may well be present in minute concentrations in a single breath. It is of interest that the classification model developed in the Van Berkel study had higher accuracy for discriminating COPD versus controls than ours. Although the breath collection methodologies differed, the analytical techniques, based on GC-ToF-MS, were similar. It may be that the large difference in demographics between the COPD and healthy cohorts in that study (the COPD group were 21 years older, and $76 \%$ were current smokers) contributed to the differences seen. Likewise the close matching of current smoking status in our cohorts may have contributed to the moderate success of our classification model, as active smoking is clearly likely to be a dominant confounder in exhaled breath analysis where data from both smokers and nonsmokers are analysed together. Indeed when we looked only at smokers with and without COPD (thus neutralising this confounding effect in the analysis), we found our model classified disease with far greater accuracy. The scatter plot (Figure 2) shows the COPD data to be clustered in one region of (but still within) the data from the healthy controls. This is consistent with the concept of COPD as a disease of accelerated lung aging [21], and it is perhaps not surprising that the metabolomic profile

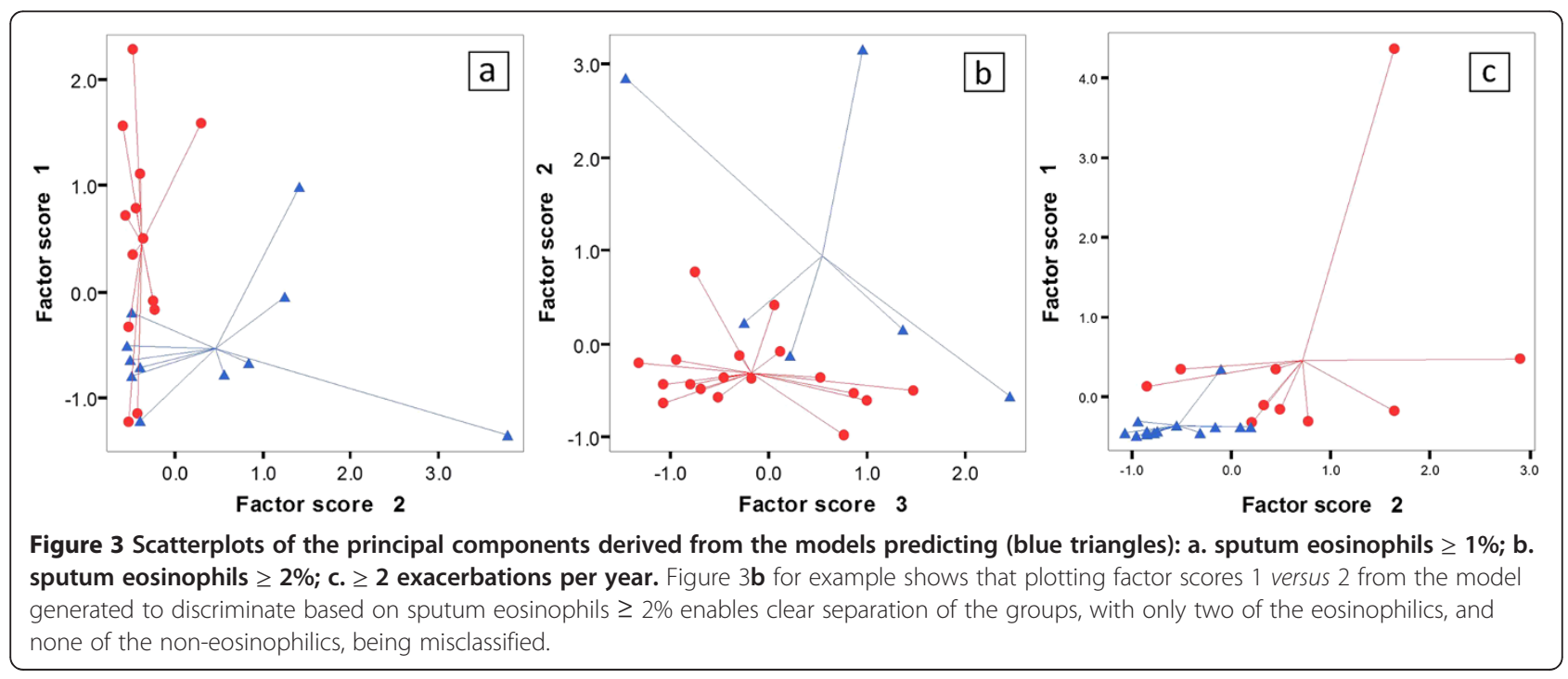




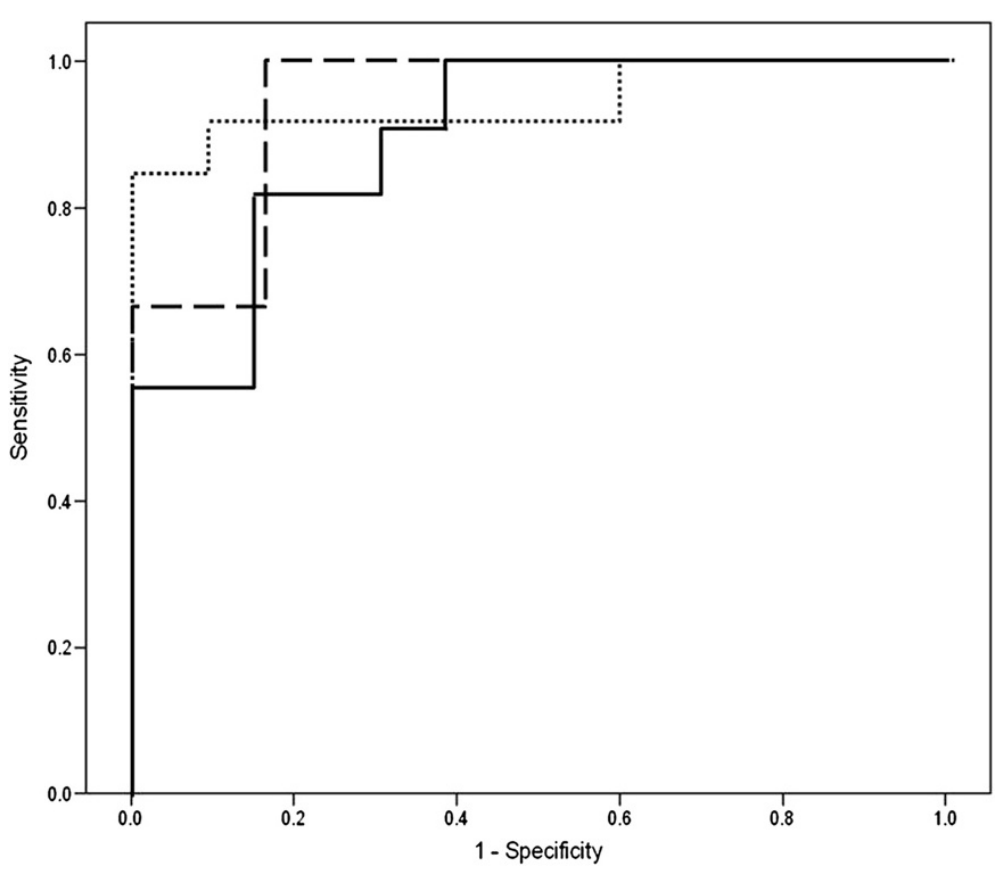

Figure 4 Receiver operating characteristics curves for subgroup comparison. Key: solid line - sputum eosinophils $\geq 1 \%$; dashed line - sputum eosinophils $\geq 2 \%$; dotted line - exacerbation frequency $\geq 2$ / yr.

of patients with this disease clusters at one extreme of normality, rather than apart from it.

Sputum eosinophilia predicts steroid-responsiveness in COPD [5], but the test is labour-intensive, time consuming, and samples are not obtainable in a significant minority of patients [22]. Whilst our technique for breath collection and analysis is currently relatively high-cost and labour-intensive, if a set of candidate biomarkers were validated for predicting steroid responsiveness, work would focus on developing and producing

Table 5 Table of putative VOCs and empirical formulae associated with sputum eosinophilia and frequent exacerbations, shown in order of decreasing strength of correlation $(r)$ between compounds and sputum eosinophil count, and number of exacerbations in the previous year

\begin{tabular}{|c|c|c|c|c|c|}
\hline Eosinophils $\geq 1 \%$ & $\mathbf{r}$ & Eosinophils $\geq 2 \%$ & $\mathbf{r}$ & Exacerbations $\geq 2$ / yr & $\mathbf{r}$ \\
\hline a-Methylstyrene $\mathrm{C}_{9} \mathrm{H}_{10}$ & -0.51 & $\begin{array}{l}\text { 1, 1'-Biphenyl, } \\
\text { 3-methyl- } \mathrm{C}_{13} \mathrm{H}_{12}\end{array}$ & -0.49 & $\begin{array}{l}\text { Undecane, 3, 7-dimethyl } \\
\mathrm{C}_{13} \mathrm{H}_{28}\end{array}$ & -0.63 \\
\hline $\begin{array}{l}\text { 3-Cyclohexen-1-ol, } \\
\text { 4-methyl-1-(1-methylethyl)-, } \\
\text { acetate } \mathrm{C}_{12} \mathrm{H}_{20} \mathrm{O}_{2}\end{array}$ & -0.51 & $\begin{array}{l}\text { dodecanoic ac methylethylester } \\
\mathrm{C}_{15} \mathrm{H}_{30} \mathrm{O}_{2}\end{array}$ & 0.31 & $\begin{array}{l}\text { 2, 2, 4, 4-Tetramethyloctane } \\
\mathrm{C}_{12} \mathrm{H}_{26}\end{array}$ & -0.58 \\
\hline $\begin{array}{l}\text { benzofuran, 4, 5, 6, } 7 \text { tetrahydro-3, } \\
\text { 6-dimethyl } \mathrm{C}_{10} \mathrm{H}_{14} \mathrm{O}\end{array}$ & 0.41 & $\begin{array}{l}\text { benzene, 1, 2, 3, } \\
\text { 4-tetramethyl- } \mathrm{C}_{10} \mathrm{H}_{14}\end{array}$ & 0.29 & $\begin{array}{l}\text { 1,4-Methanoazulene, decahydro-4, } \\
\text { 8, 8-trimethyl-9-methylene-, } \\
{[1 \mathrm{~S}-(1 a, 3 a \beta, 4 a, 8 a \beta)]-\mathrm{C}_{15} \mathrm{H}_{24}}\end{array}$ & -0.53 \\
\hline Decane, 3-methyl $\mathrm{C}_{11} \mathrm{H}_{24}$ & 0.41 & bicycle carene type $\mathrm{C}_{10} \mathrm{H}_{16}$ & 0.23 & $\begin{array}{l}\text { Naphthalene, } 2,3 \\
\text { 6-trimethyl- } \mathrm{C}_{13} \mathrm{H}_{14}\end{array}$ & -0.49 \\
\hline $\begin{array}{l}\text { Pentanoic acid, 2, 2, } \\
\text { 4-trimethyl-3-carboxyisopropyl, } \\
\text { isobutyl ester } \mathrm{C}_{16} \mathrm{H}_{30} \mathrm{O}_{4}\end{array}$ & -0.33 & $\begin{array}{l}\text { 1, 5-Heptadiene, } 2, \\
\text { 5-dimethyl-3-methylene- } \mathrm{C}_{10} \mathrm{H}_{16}\end{array}$ & 0.20 & Chlorobenzene $\mathrm{H}_{6} \mathrm{H}_{5} \mathrm{Cl}$ & -0.37 \\
\hline $\begin{array}{l}2 \text { cyclopenten 1one 3, 5, } 5 \text { trimethyl } \\
\mathrm{C}_{8} \mathrm{H}_{12} \mathrm{O}\end{array}$ & -0.31 & & & Pentadecane, 3-methyl- $\mathrm{C}_{16} \mathrm{H}_{34}$ & -0.37 \\
\hline $\begin{array}{l}2(1 \mathrm{H}) \text { Naphthalenone, } 3,5,6,7,8, \\
\text { 8a-hexahydro-4, } \\
\text { 8a-dimethyl-6-(1-methylethenyl)- } \\
\mathrm{C}_{15} \mathrm{H}_{22} \mathrm{O}\end{array}$ & 0.30 & & & & \\
\hline
\end{tabular}


small, user-friendly point-of-care sensors specifically for this purpose. We have previously shown that breath VOC profiles can also predict sputum eosinophilia in asthma [11]. Unsurprisingly, given the differences in demographics and disease processes between the studies, the specific VOCs used in the models were not the same. The identification of VOCs patterns specific to sputum inflammatory profile, and phenotypes such as "frequent exacerbators" may not only provide biomarkers for clinical use, but also could potentially provide new insights in disease pathophysiology.

Whilst absolute control of environmental VOCs is practically impossible, it is desirable to reduce background levels as much as is practicable. We use a VOCfilter in our circuit, an equilibration time of at least five minutes, and collect samples in the same room for this purpose. Even so, exogenous VOCs may be differentially handled by the airways in health and disease, and alteration in exhaled concentrations may therefore be relevant. Examples include: low-molecular weight molecules being absorbed by excessive airway secretions more readily than heavier molecules; the systemic circulation, acting as a reservoir, re-releasing environmental VOCs into the air at rates determined by cardiac output and lung circulation [23]; airway and alveolar inflammatory processes metabolising inhaled VOCs for example by oxidation; and the air trapping seen in obstructive lung disease altering the washout time for gas-phase molecules compared to healthy lungs. One approach to correcting for "exogenous" VOCs is to subtract the content of a contemporaneous environmental sample from the expired sample [24], but this oversimplifies the metabolic and physiological impact of the airways and circulation.

Our findings require validation in an independent group of subjects then definitive compound identification and calibration curves determined by injection of known standards. The origins of these compounds are as yet unknown, but hypotheses can be generated. For example six of the 11 compounds discriminating COPD from health were aldehydes, and all had strong loading onto the first principal component, an interesting finding in line with the findings of Van Berkel et al. [7]. It may be that the metabolic upregulation in the mucosa of COPD patients removes aldehydes from the air; it is known for example that the aldehyde scavengers $\mathrm{N}$-acetylcysteine and glutathione monoethyl ester completely remove unsaturated (but not saturated) aldehydes from a cigarette smoke extract [25]. There may also be an effect of ICS on suppressing exhaled aldehyde levels, supported by the contribution of undecanal to both models. Further, it may be instructive in future studies to compare these putative exhaled markers of inflammation to existing disease-relevant breath biomarkers such as leukotriene $\mathrm{B}_{4}$ and other eicosanoids [26].

\section{Conclusion}

We have demonstrated the potential of breath gas analysis for the identification of metabolomic patterns that not only can be used to discriminate health from disease (especially amongst current smokers) but also to identify clinically relevant disease phenotypes. It is now essential that these findings be validated prospectively in an independent group of patients in order to confirm that these patterns have potential for clinical use as biomarkers. Furthermore, confirmation of the identity of specific discriminatory compounds may lead to the elucidation of metabolic pathways with potential benefits for novel therapeutic targets.

\section{Abbreviations}

AUC: Area under the curve; COPD: Chronic obstructive pulmonary disease; DFA: Discriminant function analysis; FEV1: Forced expiratory volume in one second; FVC: Forced vital capacity; GC: Gas chromatography; ICS: Inhaled corticosteroids; MS: Mass spectrometry; PC: Principal component;

PCA: Principal component analysis; QC: Quality control; ROC: Receiver operating characteristics; RSD: Relative standard deviation; ToF: Time of flight; VOCs: Volatile organic compounds.

\section{Competing interests}

The authors declare that they have no competing interests.

\section{Authors' contributions}

$\mathrm{MB}, \mathrm{BI}$ and $\mathrm{RD}$ were involved in performing study procedures, data collection and analysis; DD and MM provided technical supervision and advice; DS and AW provided clinical supervision and advice and SJF provided overall project supervision. All authors were involved in study design and had input into and approved the final manuscript.

\section{Acknowledgements}

Our thanks go to GlaxoSmithKline for contributing to the funding of this study, Waters Corporation for loan of mass spectrometry equipment, and Jørgen Vestbo and Ruth Tal-Singer for their review of the manuscript. BI thanks the Universiti Sains Malaysia for funding.

\section{Author details}

${ }^{1}$ Respiratory Research Group, Faculty of Medical and Human Sciences, University of Manchester, Manchester Academic Health Science Centre, and NIHR Translational Research Facility in Respiratory Medicine, University Hospital of South Manchester, Southmoor Road, Manchester M23 9LT, UK. ${ }^{2}$ Waters Corporation, Manchester, UK. ${ }^{3}$ Lancashire Teaching Hospitals NHS Foundation Trust, Preston, UK.

Received: 12 March 2012 Accepted: 14 August 2012

Published: 23 August 2012

\section{References}

1. Rabe KF, Hurd S, Anzueto A, Barnes PJ, Buist SA, Calverley P, Fukuchi Y, Jenkins $C$, Rodriguez-Roisin R, van Weel $C$, et al: Global strategy for the diagnosis, management, and prevention of chronic obstructive pulmonary disease: GOLD executive summary. Am J Respir Crit Care Med 2007, 176(6):532-555.

2. Chronic obstructive pulmonary disease: National clinical guideline on management of chronic obstructive pulmonary disease in adults in primary and secondary care. Thorax 2004, 59(Suppl 1):1-232.

3. Vestbo J, Prescott E, Lange P: Association of chronic mucus hypersecretion with FEV1 decline and chronic obstructive pulmonary disease morbidity, Copenhagen City Heart Study Group. Am J Respir Crit Care Med 1996, 153(5):1530-1535.

4. Donaldson GC, Seemungal TAR, Bhowmik A, Wedzicha JA: Relationship between exacerbation frequency and lung function decline in chronic obstructive pulmonary disease. Thorax 2002, 57(10):847-852. 
5. Brightling CE, McKenna S, Hargadon B, Birring $S$, Green $R$, Siva R, Berry M Parker D, Monteiro W, Pavord ID, et al: Sputum eosinophilia and the short term response to inhaled mometasone in chronic obstructive pulmonary disease. Thorax 2005, 60(3):193-198.

6. Vestbo J, Rennard S: Chronic Obstructive Pulmonary Disease Biomarker(s) for Disease Activity Needed-Urgently. Am J Respir Crit Care Med 2010, 182(7):863-864.

7. Van Berkel JJ, Dallinga JW, Moller GM, Godschalk RW, Moonen EJ, Wouters EF, Van Schooten FJ: A profile of volatile organic compounds in breath discriminates COPD patients from controls. Respir Med 2010, 104(4):557-563.

8. Basanta M, Jarvis RM, Xu Y, Blackburn G, Tal-Singer R, Woodcock A, Singh D, Goodacre R, Thomas CL, Fowler SJ: Non-invasive metabolomic analysis of breath using differential mobility spectrometry in patients with chronic obstructive pulmonary disease and healthy smokers. Analyst 2010, 135(2):315-320.

9. Fens N, de Nijs SB, Peters S, Dekker T, Knobel HH, Vink TJ, Willard NP Zwinderman $\mathrm{AH}$, Krouwels $\mathrm{FH}$, Janssen $\mathrm{HG}$, et al: Exhaled air molecular profiling in relation to inflammatory subtype and activity in COPD. Eur Respir J.

10. Motta A, Paris D, Melck D, de Laurentiis G, Maniscalco M, Sofia M, Montusch $P$ : Nuclear magnetic resonance-based metabolomics of exhaled breath condensate: methodological aspects. Eur Respir J 2012, 39(2):498-500.

11. Ibrahim B, Basanta M, Cadden P, Singh D, Douce D, Woodcock A, Fowler SJ: Non-invasive phenotyping using exhaled volatile organic compounds in asthma. Thorax, 66(9):804-809.

12. Vestbo J, Anderson W, Coxson HO, Crim C, Dawber F, Edwards L, Hagan G, Knobil K, Lomas DA, MacNee W, et al: Evaluation of COPD Longitudinally to Identify Predictive Surrogate End-points (ECLIPSE). Eur Respir J 2008, 31(4):869-873.

13. Miller MR, Hankinson J, Brusasco V, Burgos F, Casaburi R, Coates A, Crapo R, Enright $P$, van der Grinten $C P$, Gustafsson $P$, et al: Standardisation of spirometry. Eur Respir J 2005, 26(2):319-338.

14. Pizzichini E, Pizzichini MM, Efthimiadis A, Hargreave FE, Dolovich J: Measurement of inflammatory indices in induced sputum: effects of selection of sputum to minimize salivary contamination. Eur Respir J 1996, 9(6):1174-1180.

15. Basanta M, Ibrahim B, Douce D, Morris M, Woodcock A, Fowler SJ: Methodology validation, intra-subject reproducibility and stability of exhaled volatile organic compounds. J Breath Res, 6(2):026002.

16. Van Berkel JJ, Dallinga JW, Moller GM, Godschalk RW, Moonen E, Wouters EF, Van Schooten FJ: Development of accurate classification method based on the analysis of volatile organic compounds from human exhaled air. J Chromatogr B Analyt Technol Biomed Life Sci 2008, 861(1):101-107.

17. Hastie AT, Moore WC, Meyers DA, Vestal PL, Li H, Peters SP, Bleecker ER: Analyses of asthma severity phenotypes and inflammatory proteins in subjects stratified by sputum granulocytes. J Allergy Clin Immunol 2010, 125(5):1028-1036. e1013.

18. Izquierdo-García JL, Puerto-Nevado L, Peces-Barba G, Pérez-Rial S, Heili S, Villa P, Castejón D, González-Mangado N, Ruiz-Cabello N: A metabonomic approach to evaluate COPD in a model of cigarette smoke exposure in mice. Metabolomics 2010, 6(4):564-573.

19. Phillips M, Altorki N, Austin JH, Cameron RB, Cataneo RN, Greenberg J, Kloss R, Maxfield RA, Munawar Ml, Pass HI, et al: Prediction of lung cancer using volatile biomarkers in breath. Cancer Biomark 2007, 3(2):95-109.

20. Zweig MH, Campbell G: Receiver-operating characteristic (ROC) plots: a fundamental evaluation tool in clinical medicine. Clin Chem 1993, 39(4):561-577

21. MacNee W: Accelerated lung aging: a novel pathogenic mechanism of chronic obstructive pulmonary disease (COPD). Biochem Soc Trans 2009, 037(4):819-823.

22. Singh D, Edwards L, Tal-Singer R, Rennard S: Sputum neutrophils as a biomarker in COPD: findings from the ECLIPSE study. Respir Res, 11:77.

23. Ashley DL, Bonin MA, Cardinali FL, McCraw JM, Wooten JV: Blood concentrations of volatile organic compounds in a nonoccupationally exposed US population and in groups with suspected exposure. Clin Chem 1994, 40(7 Pt 2):1401-1404.

24. Phillips M, Herrera J, Krishnan S, Zain M, Greenberg J, Cataneo RN: Variation in volatile organic compounds in the breath of normal humans. J Chromatogr B Biomed Sci Appl 1999, 729(1-2):75-88.
25. Facchinetti F, Amadei F, Geppetti P, Tarantini F, Di Serio C, Dragotto A, Gigli PM, Catinella S, Civelli M, Patacchini R: Alpha, beta-unsaturated aldehydes in cigarette smoke release inflammatory mediators from human macrophages. Am J Respir Cell Mol Biol 2007, 37(5):617-623.

26. Montuschi P: LC/MS/MS analysis of leukotriene B4 and other eicosanoids in exhaled breath condensate for assessing lung inflammation. J Chromatogr B Analyt Technol Biomed Life Sci 2009, 877(13):1272-80.

doi:10.1186/1465-9921-13-72

Cite this article as: Basanta et al:: Exhaled volatile organic compounds for phenotyping chronic obstructive pulmonary disease: a cross-sectional study. Respiratory Research 2012 13:72.

\section{Submit your next manuscript to BioMed Central and take full advantage of:}

- Convenient online submission

- Thorough peer review

- No space constraints or color figure charges

- Immediate publication on acceptance

- Inclusion in PubMed, CAS, Scopus and Google Scholar

- Research which is freely available for redistribution

Submit your manuscript at www.biomedcentral.com/submit
C) Biomed Central 